archives

of thermodynamics

Vol. 37(2016), No. 1, 99-112

DOI: $10.1515 /$ aoter-2016-0007

\title{
Analysis of radiative heat transfer impact in cross-flow tube and fin heat exchangers
}

\author{
MAŁGORZATA HANUSZKIEWICZ-DRAPAŁA \\ TOMASZ BURY ${ }^{1}$, KATARZYNA WIDZIEWICZ
}

Silesian University of Technology, Institute of Thermal Technology, Konarskiego 22, 44-100 Gliwice, Poland

\begin{abstract}
A cross-flow, tube and fin heat exchanger of the water - air type is the subject of the analysis. The analysis had experimental and computational form and was aimed for evaluation of radiative heat transfer impact on the heat exchanger performance. The main element of the test facility was an enlarged recurrent segment of the heat exchanger under consideration. The main results of measurements are heat transfer rates, as well as temperature distributions on the surface of the first fin obtained by using the infrared camera. The experimental results have been next compared to computational ones coming from a numerical model of the test station. The model has been elaborated using computational fluid dynamics software. The computations have been accomplished for two cases: without radiative heat transfer and taking this phenomenon into account. Evaluation of the radiative heat transfer impact in considered system has been done by comparing all the received results.
\end{abstract}

Keywords: Heat exchangers; Radiative heat transfer; Numerical model; Experimental validation

\section{Introduction}

The plate exchangers (with the mixed current) and the finned cross-flow heat exchangers, which core has the form of a bunch of pipes with flat plate fins, have a very important meaning among the currently applied heat exchangers with extended surfaces $[1,2]$. These heat exchangers are

${ }^{1}$ Corresponding Author. E-mail: tomasz.bury@polsl.pl 
usually used for heat transfer between a liquid flowing inside the tubes and a gaseous medium flowing outside the tubes, on the fins side.

A typical thermodynamic analysis of a cross-flow heat exchanger is usually aimed for determination of the heat transfer surface of the desired design and its capacity [3]. There are several simplifying assumptions made during such calculations, for example neglecting of heat losses to the surrounding, uniform flow of media through the exchanger, heat transfer coefficients determined for the average temperatures. These assumptions are fulfilled very rarely in reality and of course it affects the analytical results to some degree $[3,4]$. It is usual in such analyses that the heat transfer by the mode of radiation is also neglected. This assumption seems to be obvious for the gas-liquid type heat exchangers working at low temperatures. While considering heat exchangers operating at high temperatures the radiation heat transfer should be considered. A review of available sources allows to distinguish two cases in approach for taking into account the radiative heat transfer: only heat losses from a heat exchanger to the environment are considered $[5,6]$, both heat losses to the ambience and the radiative heat transfer to a gas flowing between fins are considered [7-9]. It should be also noted that the radiative heat transfer is very important mechanism of parasitic heat transport in cryogenic heat exchangers [10].

Investigators use different radiative heat transfer models: analytical mixed with simple numerical ones [11], as well as more sophisticated numerical [12]. Numerical approach is very convenient for the considered problem, it allows both to reproduce the accurate geometry of considered object, as well as to take into account of the nonuniform air flow and the radiative heat transport Such approach however, requires a detailed feasibility study.

The computational fluid dynamics (CFD) software ANSYS-Fluent [18] has been used in this work in order to develop a numerical model and reproduce heat transfer conditions in a recurrent segment of a tube and fin cross-flow heat exchanger. The main aim of investigations was to evaluate the impact of neglecting the radiative heat transfer in numerical model and importance of this phenomenon for the overall heat transfer in considered type of heat exchangers. 


\section{Test facility and selected experimental results}

The design of test facility is closely related to another experimental rig and investigations of media flow maldistribution impact on the tube and fin crossflow heat exchangers efficiency. These investigations have been conducted since 2001 and were reported in several publications [13-16]. Originally a typical car cooler has been analyzed. The core of this cooler has the form of a bundle with two rows of tubes ( 15 cylindrical pipes finned with the plate fins in each row, 380 fins on each pipe) and was made of aluminum. This heat exchanger has been the subject on investigations in [13] and partially in [14]. Papers [15] and [16] report the experiments made for steel heat exchangers with elliptical pipes (arranged in one and two rows) and rectangular fins.

Enlarged special models of fragments of the heat exchangers mentioned above have been built in order to check the numerical procedure responsible for determination of the heat transfer coefficient from the fins to the gas. These models are made of steel due to technical limitations. The models consist of two, three or four plate fins with respective pipe sections. Two electric heaters simulate the hot water flow inside the pipes. These models are placed in a flow channel with an observation window and are cooled by the forced air flow (see Fig. 1). The air flow rate and temperatures at the inlet and outlet are measured. The infrared thermography technique is used for measurement of the temperature field on the surface of the first fin. Several thermocouples are also installed for measuring the temperature on the other fins surfaces.

The infrared temperature measurements have been realized using ThermaCAM SC2000 camera operating at 7.5-14 $\mu \mathrm{m}$ spectral range and having the temperature measurement accuracy of 1-2 deg. The surface of the fins has been prepared for the infrared measurements by its oxidation. The emissivity of the fins surface has been determined during the preparatory experiments where the whole fins section has been heated up in an electric oven and next the K-type thermocouple was used to measure the temperature on the first fin surface in parallel with the infrared camera. The emissivity value was adjusted in the camera software in order to obtain the same temperature values. The transmissivity of the foil covering the speculum window has been assessed by the comparison of the infrared measurements realized with and without the foil. The reflected temperature compensation depended on the experiments conditions. The ambient temperature has been set as the reflected temperature value for experiments realized in 


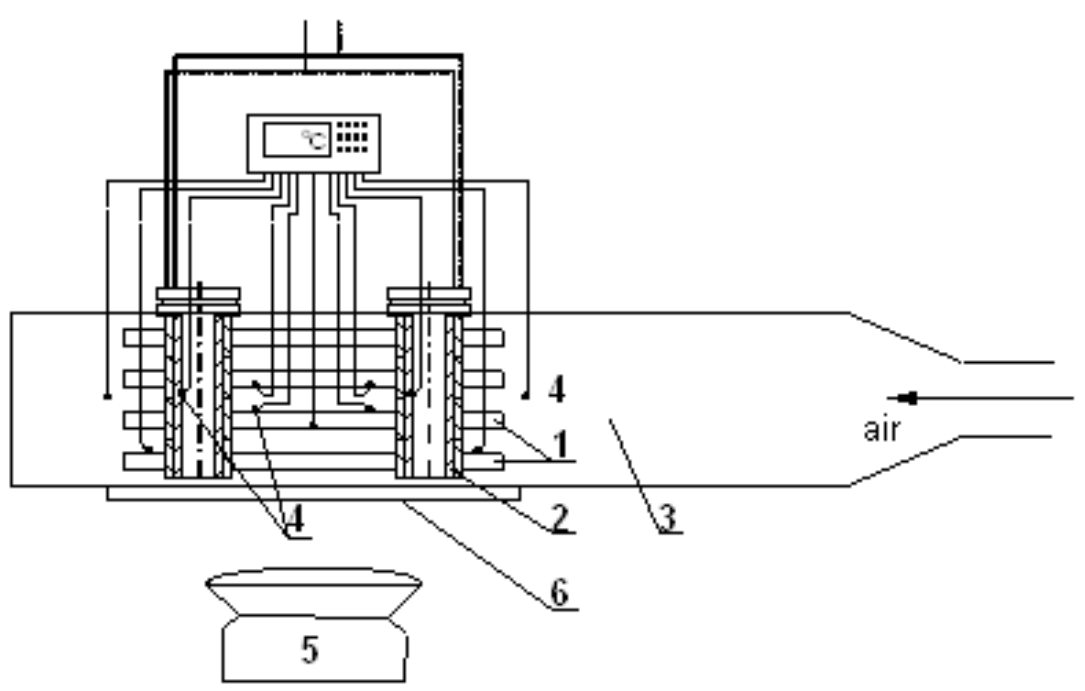

Figure 1: Simplified sketch of the test station: 1 - fins and pipe models, 2 - electric heaters, 3 - flow channel, 4 - thermocouples, 5 -infrared camera, 6 - speculum.

the spring and summer season. The reflected temperature value for the fall and winter seasons was determined by applying the Lambert's radiator on the first fin surface and setting the emissivity to 1.0 in the camera software. The K-type thermocouples (NiCr-NiAl) have been used for the temperature measurements on the fins surface as well as for the air temperature measurements.

The air flow rate was measured by the vortex type flow meter with the accuracy of $1 \%$. Two parameters have been set as independent during experiments: the temperature of the pipe internal wall and the air flow rates. The experiments started with setting the desired air flow rate. Next the electric heater power was regulated in order to obtain the given temperature on the heaters surfaces. This stage lasted from 15 up to 25 min. depending on the actual air flow rate. The crucial part of the experiment was conducted in the steady state conditions - during the time span of 20 min. each measured parameter was recorded every one minute. Following parameters have been recorded during measurements:

- air volumetric flow rate, $\dot{V}_{a}$;

- air temperature at the inlet and outlet of the fins section, $\mathrm{t}_{a, i n}$, and $\mathrm{t}_{a, \text { out }}$; 
- electric power consumed by the heaters, $\mathrm{N}_{h}$;

- electric heater surface temperature, $\mathrm{t}_{h 1}$, and, $\mathrm{t}_{h 2}$, (assumed after as the pipe inner surface temperature);

- temperatures on the fin surfaces in the measuring points (seven measuring points have been marked as L1, L2, L3, M, R1, R2, and R3);

- temperature distribution on the surface of the first fin.

Measurements have been realized for electric heaters temperature ranging from $50^{\circ} \mathrm{C}$ up to $90^{\circ} \mathrm{C}$. The results obtained for the model consisting of the four fins and round pipe sections are gathered in Tab. 1. The presented values have been recorded as the last ones during the steady state stage of each experiment.

Table 1: Selected results of experiments.

\begin{tabular}{|c||c|c|c|c|c|c|c|c|c|c|c|c|c|}
\hline \multicolumn{1}{|c||}{} & \multicolumn{10}{c|}{ Parameters } \\
\hline \multirow{2}{*}{ Experiment } & $\dot{V}_{a}$ & $t_{h 1}$ & $t_{h 2}$ & $N_{h}$ & $t_{a, \text { in }}$ & $t_{a, \text { out }}$ & $t_{L 1}$ & $t_{L 2}$ & $t_{L 3}$ & $t_{M}$ & $t_{R 1}$ & $t_{R 2}$ & $t_{R 3}$ \\
\cline { 2 - 14 } & $\mathrm{m}^{3} / \mathrm{h}$ & ${ }^{\circ} \mathrm{C}$ & ${ }^{\circ} \mathrm{C}$ & $\mathrm{W}$ & ${ }^{\circ} \mathrm{C}$ & ${ }^{\circ} \mathrm{C}$ & ${ }^{\circ} \mathrm{C}$ & ${ }^{\circ} \mathrm{C}$ & ${ }^{\circ} \mathrm{C}$ & ${ }^{\circ} \mathrm{C}$ & ${ }^{\circ} \mathrm{C}$ & ${ }^{\circ} \mathrm{C}$ & ${ }^{\circ} \mathrm{C}$ \\
\hline \hline S-1 & 25.3 & 49.5 & 50.2 & 67.4 & 24.0 & 31.4 & 45.3 & 40.0 & 49.4 & 42.3 & 37.3 & 38.0 & 37.9 \\
\hline S-2 & 30.1 & 49.2 & 50.6 & 75.2 & 24.0 & 30.8 & 43.7 & 38.3 & 47.1 & 41.4 & 35.8 & 36.1 & 36.4 \\
\hline S-3 & 35.0 & 49.6 & 50.4 & 82.8 & 24.4 & 31.4 & 42.8 & 37.0 & 45.0 & 40.7 & 34.3 & 34.4 & 34.9 \\
\hline S-4 & 40.3 & 49.1 & 50.5 & 89.1 & 24.5 & 30.4 & 41.4 & 34.7 & 41.8 & 39.3 & 32.5 & 32.1 & 33.5 \\
\hline S-5 & 44.9 & 49.7 & 50.4 & 93.9 & 22.9 & 28.4 & 38.6 & 33.8 & 43.2 & 38.9 & 31.2 & 31.4 & 31.6 \\
\hline S-6 & 25.3 & 93.7 & 90.4 & 111.0 & 23.9 & 36.6 & 56.1 & 48.3 & 60.1 & 52.4 & 41.8 & 39.7 & 42.1 \\
\hline S-7 & 30.1 & 89.5 & 90.6 & 120.6 & 24.0 & 36.0 & 54.5 & 46.4 & 57.8 & 50.7 & 41.2 & 39.1 & 41.7 \\
\hline S-8 & 34.9 & 90.8 & 90.5 & 129.7 & 24.0 & 34.5 & 52.2 & 44.3 & 55.4 & 49.4 & 40.4 & 38.7 & 41.1 \\
\hline S-9 & 40.2 & 89.3 & 89.6 & 138.6 & 24.0 & 33.7 & 48.9 & 41.8 & 52.0 & 46.2 & 37.6 & 35.6 & 38.1 \\
\hline $\mathrm{S}-10$ & 45.1 & 89.7 & 90.6 & 147.8 & 24.5 & 34.2 & 46.5 & 39.1 & 48.3 & 42.4 & 35.2 & 32.8 & 35.3 \\
\hline
\end{tabular}

The temperature distributions on the first fin surface are one of the most important results as they allow to extened comparative analysis of experimental and numerical results, thus leading to a more detailed validation. Figure 2 presents a sample thermogram.

The experimental results were used in further analysis for verification of a numerical model. The temperature distributions on the first fin surface are very important in this process, as mentioned before, but also the total heat transfer rates from the fins section to the flowing air are of the significant importance also. The total heat transfer rate may be calculated using 


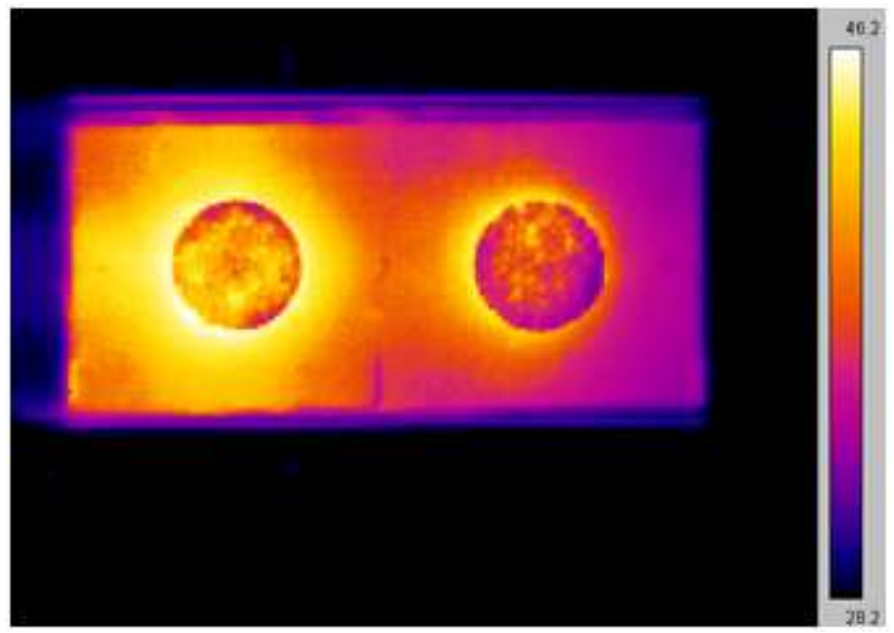

Figure 2: Sample temperature distribution on the first fin surface for S-1 experiment result of the infrared camera measurements.

the obvious formula for the air enthalpy increase, however the air temperature measurement at the outlet of the fins section seems to be of a reduced accuracy. Therefore it was assumed that the electric power consumed by the heaters is totally converted to heat and next transported to air. This parameter was measured with the uncertainty of $\pm 0.5 \mathrm{~W}$.

\section{Numerical model}

\subsection{Geometry of the model and tests of turbulence models}

All experiments described earlier have been next simulated using numerical model of the laboratory stand. The numerical model of the system under consideration was a part of the laboratory stand and contains the flow channel with the section containing ribs. The geometry of the model has been created using Gambit preprocessor [17] and it is shown in Fig. 3 together with the boundary conditions types. All remaining boundary conditions have been set as coupled (between fluid and solid part of the computational domain) and insulated walls for external surfaces of the model. The numerical model contains almost $1.5 \times 10^{6}$ of tetrahedral cells. All performed simulations have been realized using the measured air flow rate and the electric heaters surfaces temperature as the boundary conditions.

The main governing equations of the numerical model are the mass con- 


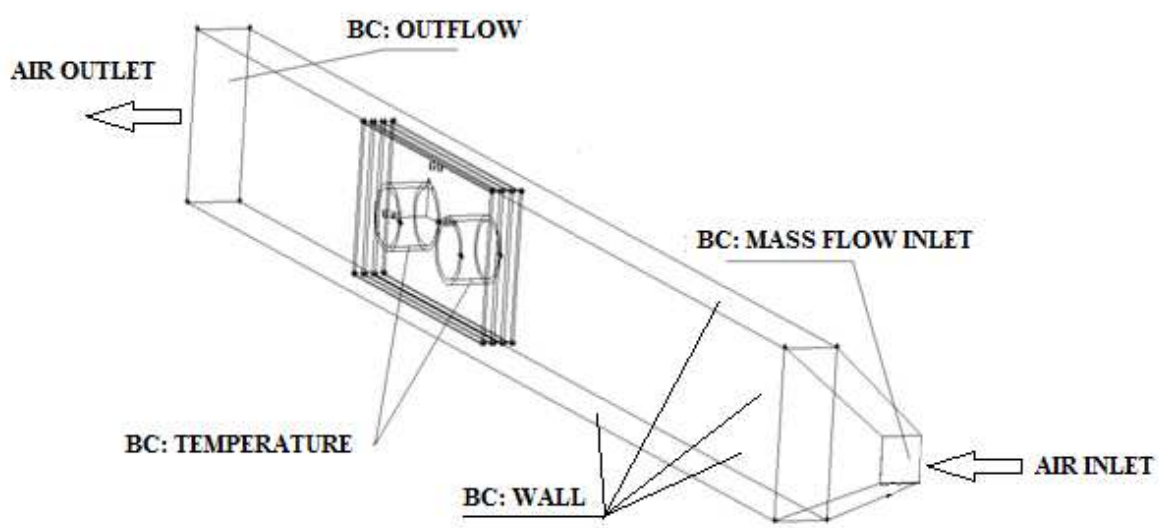

Figure 3: Geometry and boundary condition types of the numerical model.

servation equation, the momentum conservation equation and the energy conservation equation. This set of equations is supplemented by the equation of state for determination of thermophysical properties of air. The turbulence model was chosen after testing simulations. Two models have been considered: a simple two-equation $k-\varepsilon$ model and a more complicated seven-equation model of Reynolds stress transport (RSM) [18]. The testing computations have been realized for the S-9 measurement data. The previously obtained experience $[13,14]$ shown that the incompressible ideal gas model can be adopted for the analysis. The heat transfer rate equal to $131.5 \mathrm{~W}$ has been obtained for $k-\varepsilon$ model and $128.7 \mathrm{~W}$ for RSM model. The relative differences related to measured value of $138.6 \mathrm{~W}$ are $5.1 \%$ and $7.1 \%$, respectively. These values show that application of the simpler model returns the results closer to the reality. Velocity and temperature fields in characteristic planes of the numerical model have been also analyzed for more a complete evaluation. Distributions of these parameters are presented in Figs. 4-7. These results are shown for following planes (looking from the right):

- plane of the air temperature measurement before the fins section,

- plane of the first pipe axis,

- plane of the second pipe axis,

- plane of the air temperature measurement after the fins section,

- plane of the outflow. 


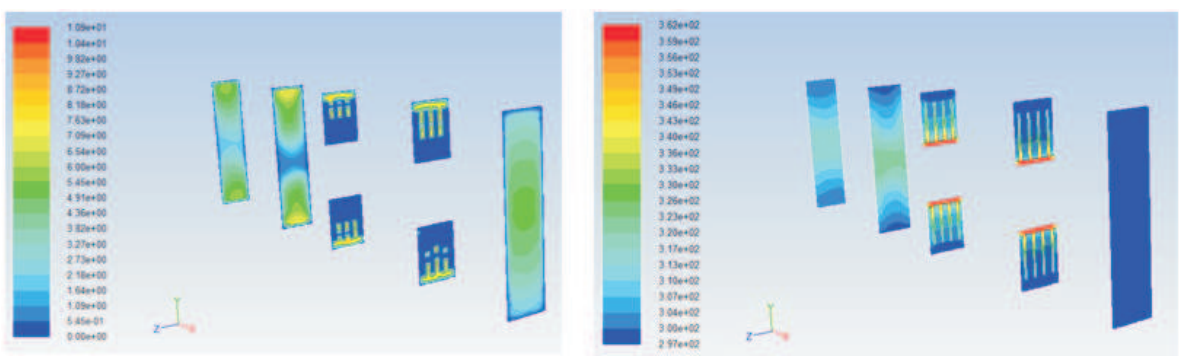

Figure 4: The air velocity (left, $\mathrm{m} / \mathrm{s}$ ) and temperature (right, $\mathrm{K}$ ) distributions for S-9 case $-k-\varepsilon$ turbulence model (vertical cross section planes perpendicular to flow direction).
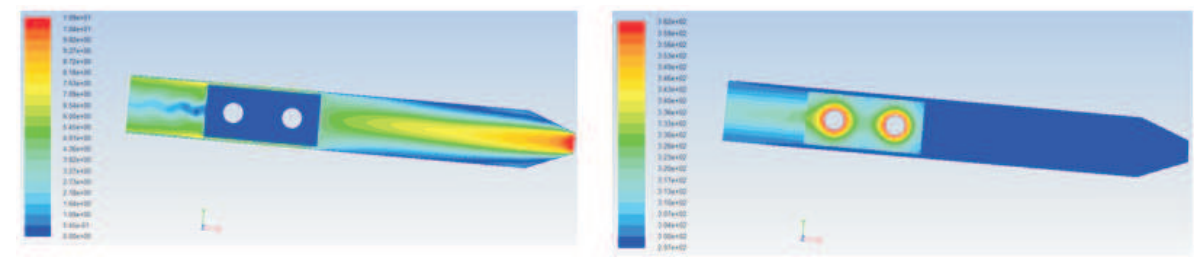

Figure 5: The air velocity (left, $\mathrm{m} / \mathrm{s}$ ) and temperature (right, $\mathrm{K}$ ) distributions for S-9 case $-k-\varepsilon$ turbulence model (vertical cross section planes parallel to flow direction).
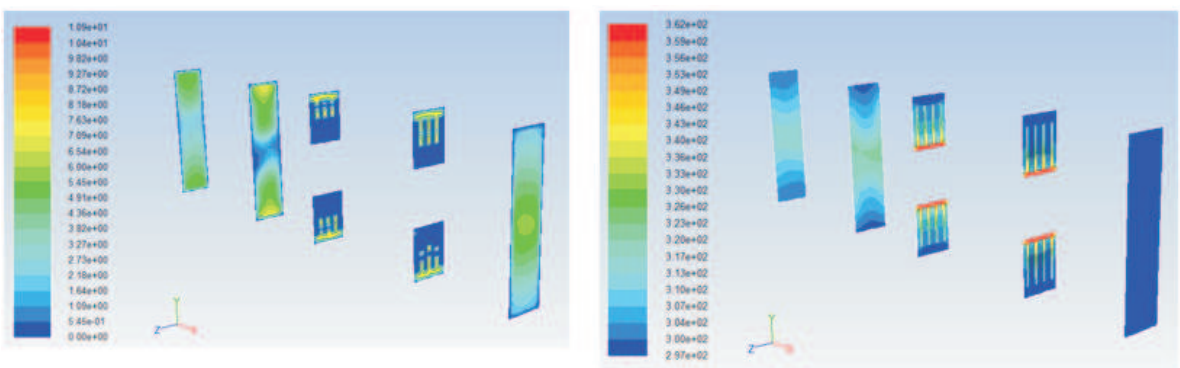

Figure 6: The air velocity (left, $\mathrm{m} / \mathrm{s}$ ) and temperature (right, K) distributions for S-9 case - RSM turbulence model (vertical cross section planes perpendicular to flow direction).

Analyzing distributions of the air velocity and temperature presented in Figs. 4-7 one may observe their similarity. The results obtained by using the $k-\varepsilon$ model are closer to the experimental ones and moreover the simulations took significantly shorter time. It was decided to apply this model of turbulence in the further analysis. 

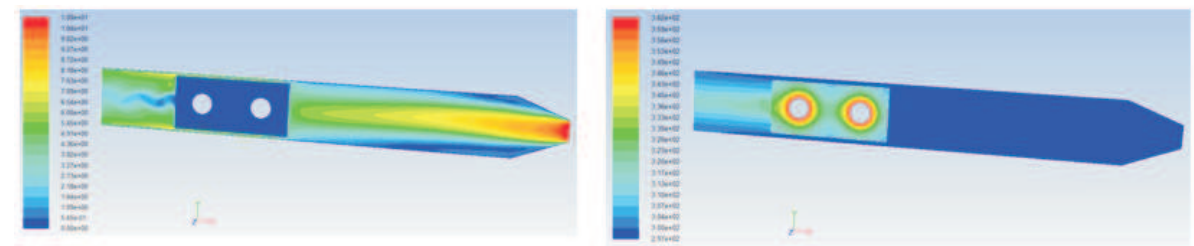

Figure 7: The air velocity (left, $\mathrm{m} / \mathrm{s}$ ) and temperature (right, K) distributions for S-9 case - RSM turbulence model (vertical cross section planes parallel to flow direction).

\subsection{Model of the radiative heat transfer - general characteristics}

A part of simulations also considered thermal radiation. The surface to surface (S2S) model of this phenomena implemented into the CFD software has been applied.

The surface-to-surface radiation model can be used to account for the radiation heat transfer in the enclosure of gray-diffuse surfaces. The heat transfer between two surfaces depends in part on their size, separation distance, and the orientation. These parameters are combined together by a geometric function called a view factor. The main assumption of the S2S model is that any absorption, emission, or scattering of radiation can be ignored. Therefore, only radiation between two surfaces (surface-to-surface) needs to be considered for the analysis [18].

The S2S radiation model assumes the surfaces to be gray and diffuse. Emissivity and absorptivity of a gray surface are independent of the wavelength. Also, by Kirchoff's, the emissivity equals the absorptivity. For a diffuse surface, the reflectivity is independent of the outgoing (or incoming) directions.

The gray-diffuse model is implemented into the Fluent code. Also, as stated earlier, for applications of interest, the transfer of radiative energy between surfaces is virtually unaffected by the medium that separates them. Thus, according to the gray-body model, if a certain amount of radiant energy is incident on a surface, a fraction is reflected, a fraction is absorbed, and a fraction is transmitted. Since for most applications the surfaces in question are opaque to thermal radiation (in the infrared spectrum), the surfaces can be considered opaque. Thus, the transmissivity can be neglected [18].

The S2S radiation model is computationally very expensive (time con- 
suming) when there are a large number of radiating surfaces. To reduce the computational time as well as the storage requirement, the number of radiating surfaces is reduced by creating surface groups - clusters. The surface clusters are made by starting from a face and adding its neighbors and their neighbors until a specified number of faces per surface cluster is collected [18].

\section{Comparative analysis}

The experimental data obtained during the analysis allows the verification of the numerical model and its main assumptions. The total heat transfer rate is one of the most important parameters. This parameter has been analyzed after the first series of simulations. The comparison of experimental, $\dot{Q}_{e x}$, and numerical, $\dot{Q}_{n u m}$, values of total heat transfer rate, and relative differences for five measurements under consideration are shown in Tab. 2. The column 'measured value' in this table contains values of the electrical power consumed by the heaters (as explained in Sec. 2). The computed values have been determined according to the CFD solutions and they express the sum of the heat fluxes, $\dot{q}_{i}(i=1, \ldots, n)$ for each surface of the fins section model multiplied by the given surface area $A_{i}$ :

$$
\dot{Q}_{\text {num }}=\sum_{i} \dot{q}_{i} A_{i}
$$

The relative differences presented in Tab. 2 have been computed as

$$
\delta=\frac{\dot{Q}_{e x}-\dot{Q}_{n u m}}{\dot{Q}_{e x}} 100 \% .
$$

Temperature distributions measurements by using the infra red camera create an additional possibility of the verification. In Figs. 8 and 9 there are presented temperature fields on the surface of the first fin for sample measurement.

The last step in the verification procedure was the comparison of temperatures measured by thermocouples with numerical predictions. Selected results are shown in Tab. 3. The relative differences of the experimental and numerical results range between 0.2 to $5.1 \%$. The agreement of the results seems to be satisfactory, even while considering the uncertainty of the measured value $( \pm 0.5 \mathrm{~W})$. The numerical outcomes are overestimated in four cases concerning the lowest air flow rates (see Tab. 1). The probable 
reason of this situation could be some problems with the turbulence model

- the flow may become transient.

Table 2: Verification of the numerical model - comparison of total heat transfer rates.

\begin{tabular}{|c|c|c|c|}
\hline Experiment & $\begin{array}{c}\text { Measured value, } \\
\mathrm{W}\end{array}$ & $\begin{array}{c}\text { Computed value, } \\
\mathrm{W}\end{array}$ & $\begin{array}{c}\text { Relative difference, } \\
\%\end{array}$ \\
\hline \hline S-1 & 67.4 & 68.3 & -1.4 \\
\hline S-2 & 75.2 & 75.4 & -0.2 \\
\hline S-3 & 82.8 & 80.5 & 2.8 \\
\hline S-4 & 89.1 & 85.1 & 4.5 \\
\hline S-5 & 93.9 & 89.5 & 4.7 \\
\hline S-6 & 111.0 & 113.3 & -2.1 \\
\hline S-7 & 120.6 & 121.2 & -0.5 \\
\hline S-8 & 129.7 & 124.6 & 3.9 \\
\hline S-9 & 138.6 & 131.5 & 5.1 \\
\hline S-10 & 147.8 & 140.7 & 4.8 \\
\hline
\end{tabular}

Table 3: Verification of the numerical model - comparison of point temperatures in degrees Celsius $\left({ }^{\circ} \mathrm{C}\right)$.

\begin{tabular}{|l|c|c|c|l|l|l|l|l|l|}
\cline { 2 - 10 } \multicolumn{2}{c|}{} & $t_{L 1}$ & $t_{L 2}$ & $t_{L 3}$ & $t_{M}$, & $t_{R 1}$ & $t_{R 2}$ & $t_{R 3}$ & $t_{a, \text { out }}$ \\
\hline \multirow{2}{*}{ S-4 } & measurement & 40.4 & 41.5 & 34.5 & 43.9 & 39.8 & 40.6 & 33.9 & 30.4 \\
\cline { 2 - 10 } & simulation & 40.1 & 40.9 & 33.8 & 43.5 & 39.4 & 39.9 & 33.3 & 29.9 \\
\hline \multirow{2}{*}{ S-7 } & measurement & 55.5 & 56.2 & 47.1 & 60.5 & 54.6 & 55.1 & 46.3 & 36.0 \\
\cline { 2 - 10 } & simulation & 56.2 & 57.7 & 48.0 & 61.1 & 55.4 & 56.5 & 47.2 & 36.3 \\
\hline
\end{tabular}

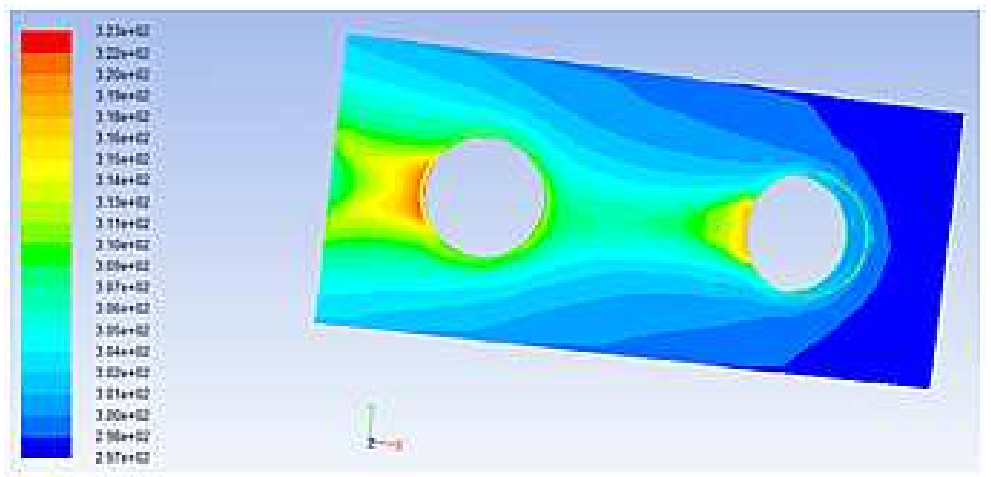

Figure 8: Temperature distribution on the first fin surface i kelvins $(\mathrm{K})$ - simulation for S-4 measurement. 


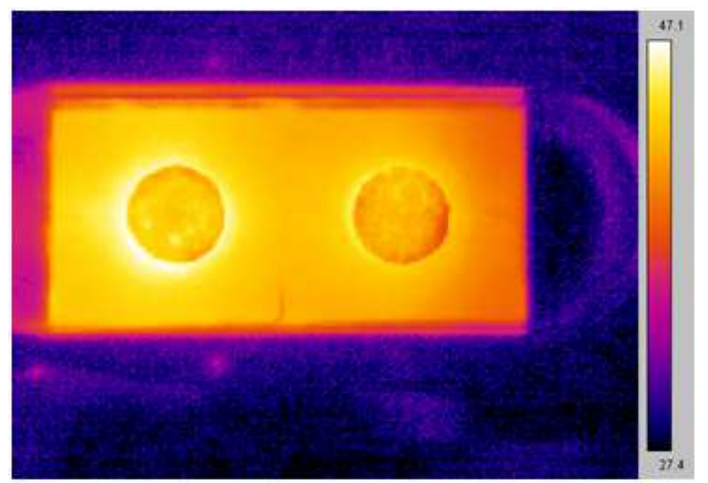

Figure 9: Temperature distribution on the first fin surface in degrees Celsius $\left({ }^{\circ} \mathrm{C}\right)-\mathrm{S}-4$ measurement.

As mentioned earlier the main aim of this combined experimental and numerical analysis was to evaluate the impact of the radiative heat transfer in the considered type of heat exchangers. It was expected that this phenomenon may be significant at higher temperatures, so the analysis has been done for measurements realized at $90^{\circ} \mathrm{C}-\mathrm{S}-6$ to S-10. The results of these computations have been compared with the outcomes of previously realized simulations (see Tab. 2). In Tab. 4 there are presented the results of the comparison. The columns 'computed value' and 'relative difference' contain values of the total heat transfer rates and relative differences respectively which were determined according to the Eqs. (1) and (2). The last column in Tab. 2 presents the relative differences of the computational results obtained with the radiative heat transfer considered and not considered.

Analyzing values from Tab. 4 it can be seen that taking the radiative heat transfer into account allows for more realistic reproduction of the observed processes. The total heat transfer rates are closer to the measured ones than previously obtained (without the radiation). It is however important that the time of computations is almost four times longer.

\section{Conclusions}

The total heat transfer rates are obviously increased by including the radiation. This effect improves the compliance of experimental and numerical results at higher air flow rates. However, the data gathered in Tab. 4 show 
Table 4: Analysis of the radiative heat transfer impact.

\begin{tabular}{|c|l|l|l|l|}
\hline \multirow{2}{*}{ Experiment } & $\begin{array}{l}\text { Measured } \\
\text { value }\end{array}$ & $\begin{array}{l}\text { Computed } \\
\text { value }\end{array}$ & $\begin{array}{l}\text { Relative } \\
\text { difference }\end{array}$ & $\begin{array}{l}\text { Relative difference } \\
\text { of the numerical } \\
\text { results with and } \\
\text { without radiation }\end{array}$ \\
\cline { 2 - 5 } & $\mathrm{W}$ & $\mathrm{W}$ & $\%$ & $\%$ \\
\hline \hline S-6 & 111.0 & 115.1 & -3.7 & -1.6 \\
\hline S-7 & 120.6 & 122.3 & -1.4 & -0.9 \\
\hline S-8 & 129.7 & 126.2 & 2.7 & -1.3 \\
\hline S-9 & 138.6 & 134.2 & 3.2 & -2.0 \\
\hline S-10 & 147.8 & 142.7 & 3.5 & -1.4 \\
\hline
\end{tabular}

that the relative differences of the results including and excluding radiation are small - ranging from $0.9 \%$ to $2.0 \%$. There are two main reasons of such situation: the construction of the heat exchanger makes that surfaces which can 'see' each other have similar temperature and the air has a very weak optical activity. The simulations have been conducted for the highest temperature in the considered system. Thus, it could be expected even minor meaning of the radiative heat transfer at lower temperatures.

Summarizing the results of experimental and numerical analysis it may be stated that the heat transfer by radiation has the minor significance for the total heat transfer rates in the considered tube abd fin crossflow heat exchangers. Therefore, it can be neglected in numerical models. Using the modeling methodology applied in this investigation it is possible to take the radiation into account, but it is very time consuming. Such approach may be useful and necessary in high temperature heat exchangers or while gases are more active optically (has more complex molecules), as the flue gases for example.

Received 22 July 2015, revised 19 May 2016

\section{References}

[1] Rogiens F., Baelmans M.: Towards maximal heat transfer rate densities for small-scale high effectiveness parallel plate heat exchangers. Int. J. Heat Mass Tran. 53(2010), 605-614.

[2] Mitrovic J. (ED.): Heat exchangers - basic design applications. InTech, Rijeka 2012, ISBN 978-953-51-0278-6,. 
[3] Kays W.M., London A.L.: Compact Heat Exchangers, 3rd Edn., Krieger Publishing Company, , Malabar 1998, EAN 9781575240602.

[4] Shah R.K., Sekulic D.P.: Fundamentals of heat exchanger design. Wiley and Sons, New Jersey 2003.

[5] Peterson R.B., Vanderhoff J.A.: Analysis of a Bayonet-type counterflow heat exchanger with axial heat conduction and radiative heat loss. Numer. Heat Tr. AAppl., 40(2001), 203-219.

[6] Mathew B., Hegab H.: Modeling non-adiabatic counter flow microchannel heat exchangers. App. Therm. Eng. 58(2013), 1-2, 22-29.

[7] Mori Y., Yamada Y., HiJikata K.: Radiation effects on performances of radiative gas heat exchangers at high temperatures. Int. J. Heat Mass Tran. 23(1980), 8, 10791089.

[8] Borodulya V.A., Kovensky V.I.: Radiative heat transfer between a fluidized bed and a surface. Int. J. Heat Mass Tran. 26(1983), 2, 277-287.

[9] Bolea I., Romeo L.M., PAllarČs D.: Heat transfer in the external heat exchanger of oxy-fuel fluidized bed boilers. Appl. Therm. Eng. 66(2014), 1-2, 75-83.

[10] Shuangtao C., Yu H., Hongli Z., Lan X.: A numerical model of thermal analysis for woven wire screen matrix heat exchanger. Cryogenics 49(2009), 9, 482-489.

[11] Contento G., Oliviero M., Bianco N., Naso V.: Prediction of radiative heat transfer in metallic foams. Int. J. Therm. Sci. 76(2014), 147-154.

[12] Coelho P.J.: Advances in the discrete ordinates and finite volume methods for the solution of radiative heat transfer problems in participating media. J. Quant. Spectrosc. Ra. 145(2014), 121-146.

[13] Piątek R.: Thermal analysis of plate fin and tube heat exchanger with unequal inlet of media. PhD thesis, Sielsian University of Technology, Gliwice 2003. (in Polish)

[14] Bury T., SkŁadzień J., Hanuszkiewicz-Drapaza M.: Experimental and numerical analyses of a non-uniform agents flow impact on a finned cross-flow heat exchanger effectiveness. In: Proc. 22nd Int. Conf. on Efficiency, Cost, Optimization, Simulation and Environmental Impact of Energy Systems - ECOS 2009, Foz do Iguacu, Parana, August 31 - September 3, 2009 (CD ROM).

[15] Bury T., SkŁadzień J., Widziewicz K.: Experimental and numerical analyses of finned cross flow heat exchangers efficiency under non-uniform gas inlet flow conditions. Arch. Thermodyn. 31(2010), 4, 133-144.

[16] WidzIEwICZ K.: Thermodynamic analysis of a crossflow heat exchanger including non-uniform inlet of media and radiative heat transfer. $\mathrm{PhD}$ thesis, Sielsian University of Technology, Gliwice 2014 (in Polish).

[17] FLUENT INC.: GAMBIT 2.4 User's Guide. Lebanon 2007.

[18] ANSYS INC.: ANSYS Fluent User's Guide. Release 14.0. Canonsburg 2011. 